\title{
Electric quadrupole transitions in Ni XVIII
}

\author{
E. Charro ${ }^{1}$, I. Martín ${ }^{1}$, and D. Bielińska-Wagż $\dot{\mathbf{z}}^{2,3}$ \\ 1 Departamento de Química Física, Universidad de Valladolid, 47011 Valladolid, Spain \\ 2 Instytut Fizyki, Uniwersytet Mikołaja Kopernika, Grudziądzka 5, 87-100 Toruń, Poland \\ 3 MPI für Astrophysik, P.O. Box 1523, D-85740 Garching, Germany
}

Received May 3; accepted July 26, 2000

\begin{abstract}
Relativistic Quantum Defect Orbital (RQDO) calculations have been performed in the LS coupling scheme on electric quadrupole (E2) transitions between levels belonging to several astrophysically important configurations of Ni XVIII. A number of line strengths are reported and compared with the ones found in the literature. A good agreement with the comparative data as well as the expected systematic behaviour of the RQDO line strengths along the spectral series confirms earlier conclusions about the quality of the RQDO wavefunctions.
\end{abstract}

Key words: atomic data

\section{Introduction}

Because of their nuclear stability, iron group elements (especially the even- $Z$ ones without nuclear spin) are frequently encountered in stellar spectra. The lower, I and II, ionization states can be observed in the photosphere, while higher ionization is seen in the emission lines of the chromosphere with its steep rise of ionic temperature, A-type stars constitute important examples of this. Moreover, forbidden transitions are observed in various astronomical objects, where their study is important for diagnostic purposes. For highly charged ions, transitions from metastable levels occur at much longer wavelengths than other transitions in the same ion. This can provide information on the thermal Doppler effect.

Emission lines arising from transitions in Ni XVIII are frequently observed in the spectra of astrophysical objects, such as the solar transition region, Corona (Vernazza \& Reeves 1978; Sandlin et al. 1986) and in fusion plasmas (Janev 1991). They may be used to derive electron temperatures of the emitting region through diagnostic line ratios, as first pointed out by Flower \& Nussbaumer (1975). A knowledge of the nickel spectrum is also required for

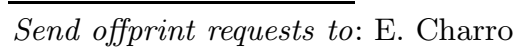

the study of impurities injected into Tokamak plasmas (Breton et al. 1979) of fusion research which originate from the nickel alloy liner currently often chosen for these devices.

Ni XVIII belongs to the sodium isolectronic sequence, with a $[\mathrm{Ne}] 3 \mathrm{~s}$ configuration for the ground state. Experimentally, a resonant photo-pumping scheme for driving lasing action in Ni XVIII and other heavier ions ( $\mathrm{Cu}$ XIX, Zn XX, etc.) has been proposed by Nielsen (1992). However, to calculate reliable electron temperatures through sensitive equation line ratios for Ni XVIII, accurate atomic data must be employed (Keenan 1992). Theoretically, many calculations have been done for the ions isoelectronic with $\mathrm{Na}$, most of them corresponding to allowed transitions. Theoretical E2 $\mathrm{S}$ and $f$-values are available in the literature: for the three ions with $Z=26,27$ and 28, $S$-values have been calculated by Tull et al. (1972); along the sodium sequence up to $Z=26$, oscillator strengths have been publised by Biemont \& Godefroid (1978); and later, Godefroid et al. (1985) have reported values for $3 \mathrm{~s}^{2} \mathrm{~S}-3 \mathrm{~d}^{2} \mathrm{D}$ forbidden transitions along the sodium sequence up to $Z=26$. Recently, theoretical results about electric quadrupole transition probabilities for the Na-like ions $\mathrm{Ba}^{45+}$ through $\mathrm{U}^{81+}$ have been reported (Baik et al. 1991).

Zhang et al. (1989) have reported collision strengths for several Na-like ions with nuclear charge $Z=22,26$, 30 and 34 , etc., using the distorted wave method. More recently, the R-matrix method has been used to calculate electron collision strengths for the forbidden and allowed transitions among the seven lowest states of Ni XVIII (Mohan et al. 1996).

Exploring the web pages, excellent databases containing wavelengths and transition probabilities for allowed and forbidden lines in atoms and ions - see p.e. CHIANTI (http://wwwsolar.nlr.navy.mil/chianti.html) can be found. However, data on E2 transition probabilities of Ni XVIII have not been found. 
The most extensive data available in the literature are the multiplet $S$-values calculated by Tull et al. (1972) using Hartree-Fock orbital wavefunctions of frozen-core type, and a critical compilation by Fuhr et al. (1988) of transition probability data and $S$-values for forbidden lines of Ni XVIII among other ions. The references given by Fuhr et al. (1988) are calculations dating from 1965 (Krueger \& Czyzak) and 1972 (Tull et al.). This critical compilation is also available at the NIST database (http://www.physics.nist.gov/fvalbib).

To our knowledge, there are no recent calculations of transition probability data for forbidden lines in relation with this ion, Ni XVIII. On this basis, we have considered that there is room for new calculations on E2 forbidden lines of Ni XVIII.

For many years we have applied the Quantum Defect Orbital method, both in its non-relativistic (QDO) (Simons 1974; Martín \& Simons 1975, 1976) and its relativistic (RQDO) (Martín \& Karwowski 1991; Karwowski \& Martín 1991) versions, to the calculation of oscillator strengths and photoionization cross sections of a rather large number of atomic species, of different degree of complexity (Biémont et al. 1998; Charro et al. 1999; Charro \& Martín 1999a, 1999b, 2000a, 2000b), including several isoelectronic sequences (see, e.g. Martín et al. 1993; Martín et al. 1994; Charro et al. 1996, 1997, 2000; Charro \& Martín 1998 and references therein).

The RQDO formalism, as opposed to sophisticated and costly self-consistent-field procedures, is a simple but reliable analytical method based on a model Hamiltonian that has the great advantage of the computational effort not being increased as the atomic system dealt with becomes heavier. It has been found that the RQDO orbitals behave rather well at intermediate and, in particular, large radial distances. These are, in most cases, the regions that contribute more strongly to the transition moment. The convenience of employing exactly solvable model potentials for calculating atomic transition probabilities manifest itself not only from a practical point of view but also because of the involved physical implications, when they are capable of achieving a good balance between computational effort and accuracy of results.

In the present work, electric quadrupole line strengths for several multiplets as well as their lines corresponding to transitions of Ni XVIII have been computed with the RQDO formalism. The $S$-values have been calculated on an individual basis, not from the application of the LScoupling rules within multiplets. We find the direct calculation of fine-structure line strengths to be interesting from a spectroscopic point of view, given their usefulness in the spectral analysis in astrophysics and fusion plasma research. A general good agreement has been found between our data and other results. It is worth pointing out that this is the second time the RQDO procedure is applied to E2 transitions, which required the elaboration of the pertinent computer code.
Table 1. Line strengths for the $n \mathrm{~s} \rightarrow n^{\prime} \mathrm{d}$ fine-structure and multiplet transitions

\begin{tabular}{|c|c|c|c|}
\hline Transition & ${ }^{2} \mathrm{~S}_{1 / 2}-{ }^{2} \mathrm{D}_{3 / 2}$ & ${ }^{2} \mathrm{~S}_{1 / 2}-{ }^{2} \mathrm{D}_{5 / 2}$ & ${ }^{2} \mathrm{~S}-{ }^{2} \mathrm{D}$ \\
\hline $3 \mathrm{~s} \rightarrow 3 \mathrm{~d}$ & $\begin{array}{l}0.761(-1) \\
0.74(-1)\end{array}$ & $\begin{array}{l}0.114 \\
0.110\end{array}$ & $\begin{array}{l}0.191 \\
0.184\end{array}$ \\
\hline $3 \mathrm{~s} \rightarrow 4 \mathrm{~d}$ & $\begin{array}{l}0.521(-1) \\
0.58(-1)\end{array}$ & $\begin{array}{l}0.778(-1) \\
0.86(-1)\end{array}$ & $\begin{array}{l}0.130 \\
0.144\end{array}$ \\
\hline $3 \mathrm{~s} \rightarrow 5 \mathrm{~d}$ & $\begin{array}{l}0.690(-2) \\
-\end{array}$ & $\begin{array}{l}0.104(-1) \\
0.11(-1)\end{array}$ & $\begin{array}{l}0.173(-1) \\
0.181(-1)\end{array}$ \\
\hline $3 \mathrm{~s} \rightarrow 6 \mathrm{~d}$ & $\begin{array}{l}0.210(-2) \\
-\end{array}$ & $\begin{array}{l}0.315(-2) \\
-\end{array}$ & $\begin{array}{l}0.525(-2) \\
0.532(-2)\end{array}$ \\
\hline $3 \mathrm{~s} \rightarrow 7 \mathrm{~d}$ & $\begin{array}{l}0.905(-3) \\
-\end{array}$ & $\begin{array}{l}0.138(-2) \\
-\end{array}$ & $\begin{array}{l}0.229(-2) \\
0.229(-2)\end{array}$ \\
\hline $3 \mathrm{~s} \rightarrow 8 \mathrm{~d}$ & $\begin{array}{l}0.489(-3) \\
-\end{array}$ & $\begin{array}{l}0.736(-3) \\
-\end{array}$ & $\begin{array}{l}0.123(-2) \\
0.120(-2)\end{array}$ \\
\hline $4 \mathrm{~s} \rightarrow 4 \mathrm{~d}$ & $\begin{array}{l}0.114(+1) \\
0.113(+1)\end{array}$ & $\begin{array}{l}0.171(+1) \\
0.170(+1)\end{array}$ & $\begin{array}{l}0.285(+1) \\
0.283(+1)\end{array}$ \\
\hline $4 \mathrm{~s} \rightarrow 5 \mathrm{~d}$ & $\begin{array}{l}0.355 \\
0.393\end{array}$ & $\begin{array}{l}0.530 \\
0.59\end{array}$ & $\begin{array}{l}0.885 \\
0.983\end{array}$ \\
\hline $4 \mathrm{~s} \rightarrow 6 \mathrm{~d}$ & $\begin{array}{l}0.471(-1) \\
0.50(-1)\end{array}$ & $\begin{array}{l}0.706(-1) \\
0.74(-1)\end{array}$ & $\begin{array}{l}0.118 \\
0.124\end{array}$ \\
\hline $4 \mathrm{~s} \rightarrow 7 \mathrm{~d}$ & $\begin{array}{l}0.141(-1) \\
0.15(-1)\end{array}$ & $\begin{array}{l}0.213(-1) \\
0.22(-1)\end{array}$ & $\begin{array}{l}0.354(-1) \\
0.364(-1)\end{array}$ \\
\hline $4 \mathrm{~s} \rightarrow 8 \mathrm{~d}$ & $\begin{array}{l}0.614(-2) \\
-\end{array}$ & $\begin{array}{l}0.923(-2) \\
-\end{array}$ & $\begin{array}{l}0.154(-1) \\
0.156(-1)\end{array}$ \\
\hline
\end{tabular}

In this and the remaining tables, $A(B)$ denotes $A \cdot 10^{(B)}$. $S$-values are given in atomic units.

The first entry corresponds to RQDO $S$-values from this work. The second entry corresponds to comparative values.

For the fine-structure lines: Critical compilation (Fuhr et al. 1988).

For the multiplets: Tull et al. (1972).

\section{Relativistic quantum defect orbital method}

The Relativistic Quantum Defect Orbital (RQDO) method has been described in detail in previous papers (Karwowski \& Martín 1991; Martín et al. 1993). Therefore, we shall only briefly summarise its most fundamental aspects.

The relativistic quantum defect orbitals are determined by solving analytically the quasi-relativistic scalar second-order Dirac-like equation, obtained after 
Table 2. Line strengths for the $n \mathrm{p} \rightarrow n^{\prime} \mathrm{p}$ fine-structure and multiplet transitions

\begin{tabular}{|c|c|c|c|c|}
\hline Transition & ${ }^{2} \mathrm{P}_{1 / 2}^{\mathrm{o}}-{ }^{2} \mathrm{P}_{3 / 2}^{\mathrm{o}}$ & ${ }^{2} \mathrm{P}_{3 / 2}^{\mathrm{o}}-{ }^{2} \mathrm{P}_{1 / 2}^{\mathrm{o}}$ & ${ }^{2} \mathrm{P}_{3 / 2}^{\mathrm{o}}-{ }^{2} \mathrm{P}_{3 / 2}^{\mathrm{o}}$ & ${ }^{2} \mathrm{P}^{\mathrm{o}}-{ }^{2} \mathrm{P}^{\mathrm{o}}$ \\
\hline $3 p \rightarrow 4 p$ & $\begin{array}{l}0.383(-1) \\
0.39(-1)\end{array}$ & $\begin{array}{l}0.418(-1) \\
0.39(-1)\end{array}$ & $\begin{array}{l}0.404(-1) \\
0.39(-1)\end{array}$ & $\begin{array}{l}0.120 \\
0.118\end{array}$ \\
\hline $3 p \rightarrow 5 p$ & $\begin{array}{l}0.355(-2) \\
-\end{array}$ & $\begin{array}{l}0.364(-2) \\
-\end{array}$ & $\begin{array}{l}0.363(-2) \\
-\end{array}$ & $\begin{array}{l}0.108(-1) \\
0.105(+1)\end{array}$ \\
\hline $3 \mathrm{p} \rightarrow 6 \mathrm{p}$ & $\begin{array}{l}0.101(-2) \\
-\end{array}$ & $\begin{array}{l}0.101(-2) \\
-\end{array}$ & $\begin{array}{l}0.102(-2) \\
-\end{array}$ & $\begin{array}{l}0.304(-2) \\
0.293(-2)\end{array}$ \\
\hline $4 \mathrm{p} \rightarrow 5 \mathrm{p}$ & $\begin{array}{l}0.370 \\
0.387\end{array}$ & $\begin{array}{l}0.403 \\
0.387\end{array}$ & $\begin{array}{l}0.390 \\
0.387\end{array}$ & $\begin{array}{l}0.116(+1) \\
0.116(+1)\end{array}$ \\
\hline $4 p \rightarrow 6 p$ & $\begin{array}{l}0.300(-1) \\
0.30(-1)\end{array}$ & $\begin{array}{l}0.306(-1) \\
0.30(-1)\end{array}$ & $\begin{array}{l}0.306(-1) \\
0.30(-1)\end{array}$ & $\begin{array}{l}0.912(-1) \\
0.899(-1)\end{array}$ \\
\hline $5 p \rightarrow 6 p$ & $\begin{array}{l}0.211(+1) \\
0.221(+1)\end{array}$ & $\begin{array}{l}0.231(+1) \\
0.221(+1)\end{array}$ & $\begin{array}{l}0.222(+1) \\
0.221(+1)\end{array}$ & $\begin{array}{l}0.663(+1) \\
0.663(+1)\end{array}$ \\
\hline
\end{tabular}

See footnotes in Table 1.

decoupling the radial, two-component Dirac equation, through a non-unitary transformation.

$\left[-\frac{\mathrm{d}^{2}}{\mathrm{~d} r^{2}}+\frac{\Lambda(\Lambda+1)}{r^{2}}-\frac{2 Z_{\text {net }}^{\prime}}{r}\right] \psi_{k}^{\mathrm{RD}}=2 \mathrm{e}^{\mathrm{RD}} \psi_{k}^{\mathrm{RD}}$,

with

$\Lambda=\eta-n+l-\delta^{\prime}+c$

$Z_{\text {net }}^{\prime}=Z_{\text {net }}\left(1+\alpha^{2} E^{x}\right)$

$\mathrm{e}^{\mathrm{RD}}=-\frac{\left(Z_{\text {net }}^{\prime}\right)^{2}}{2\left(\eta-\delta^{\prime}\right)^{2}}=E^{x} \frac{\left(1+\alpha^{2} E^{x} / 2\right)}{\left(1+\alpha^{2} E^{x}\right)^{2}}$.

$\eta$ is the relativistic principal quantum number, $n$ and $l$ are the principal and orbital angular momentum quantum numbers, $\delta^{\prime}$ is the relativistic quantum defect, $c$ is an integer chosen to ensure the normalizability of the wavefunction and its correct nodal structure; $Z_{\text {net }}^{\prime}$ is the scaled nuclear charge acting on the valence electrons at large radial distances; $E^{x}$ is the experimentally measured energy, and $\alpha$ is the fine structure constant. Atomic units are used throughout. Since the effective Hamiltonian in Eq. (1) includes a screening term, the quantum defect orbitals are approximately valid in the core region of space. Core polarization effects are implicitly included in the calculations given that they are accounted for in the $\Lambda$ parameter of the model Hamiltonian. On the other hand, given the one-electron nature of the RQDO formalism, it can be expected to perform better in highly excited states, where the active electron interacts less with the core and other valence electrons, than in low-lying energy states. The relativistic quantum defect orbitals lead to closed-form analytical expresions for the transition integrals. This allows us to calculate transition probabilities and oscillator strengths by simple algebra and with a high effectiveness/cost ratio.

Our methodology supplies one-electron radial wavefunctions, characterized by the $n, l$ and $j$ quantum numbers (Martín \& Karwowski 1991), that we employ in the transition matrix elements for the initial and final states of the active electron. These correspond to levels of a given $L, S$ and $J$ symmetry in many-electron atoms. We take care of the presence of the remaining electrons by including the appropriate angular factors in the line strengths. Thus, the electric quadrupole line strength for a transition between two states, is given by the equation

$$
\begin{aligned}
S\left(n l j, n^{\prime} l^{\prime} j^{\prime}\right)= & \frac{2 J+1}{2 S+1}\left(2 J^{\prime}+1\right)<L\left\|C^{(2)}\right\| L^{\prime}>^{2} \\
& \times\left|<R_{n l j}\right| Q(r)\left|R_{n^{\prime} l^{\prime} j^{\prime}}>\right|^{2}
\end{aligned}
$$

where $Q(r)$ is the quadrupole transition operator, $r^{2}$, and $<L\left\|C^{(2)}\right\| L^{\prime}>$ is the pertinent reduced matrix element.

The relationships between the line strength $S$ (in atomic units, $e^{2} a_{\mathrm{o}}^{4}$ ), the oscillator strength $f$ (dimensionless), and the transition probability $A$ (in $\mathrm{s}^{-1}$ ) are given by

$$
\begin{aligned}
& g^{\prime} A=\left(8 \pi^{2} \hbar \alpha / m \lambda^{2}\right) g f=\left(6.670310^{15} / \lambda^{2}\right) g f \\
& g^{\prime} A=\left(32 \pi^{5} \alpha c a_{\mathrm{o}}^{4} / 15 \lambda^{5}\right) S_{\mathrm{E} 2}=\left(1.1199510^{18} / \lambda^{5}\right) S_{\mathrm{E} 2}
\end{aligned}
$$

where $\lambda$ is the transition wavelength (in $\AA$ ), and $g^{\prime}$ and $g$ are the degeneracies of the upper and lower states, respectively. 
Table 3. Line strengths for the $n \mathrm{p} \rightarrow n^{\prime}$ f fine-structure and multiplet transitions

\begin{tabular}{|c|c|c|c|c|}
\hline Transition & ${ }^{2} \mathrm{P}_{1 / 2}^{\mathrm{o}}-{ }^{2} \mathrm{~F}_{5 / 2}^{\mathrm{o}}$ & ${ }^{2} \mathrm{P}_{3 / 2}^{\mathrm{o}}-{ }^{2} \mathrm{~F}_{5 / 2}^{\mathrm{o}}$ & ${ }^{2} \mathrm{P}_{3 / 2}^{\mathrm{o}}-{ }^{2} \mathrm{~F}_{7 / 2}^{\mathrm{o}}$ & ${ }^{2} \mathrm{P}^{\mathrm{o}}-{ }^{2} \mathrm{~F}^{\mathrm{o}}$ \\
\hline $3 p \rightarrow 4 f$ & $\begin{array}{l}0.207 \\
0.201\end{array}$ & $\begin{array}{l}0.608(-1) \\
0.57(-1)\end{array}$ & $\begin{array}{l}0.365 \\
0.345\end{array}$ & $\begin{array}{l}0.633 \\
0.603\end{array}$ \\
\hline $3 p \rightarrow 5 f$ & $\begin{array}{l}0.684(-2) \\
-\end{array}$ & $\begin{array}{l}0.186(-2) \\
-\end{array}$ & $\begin{array}{l}0.112(-1) \\
0.12(-1)\end{array}$ & $\begin{array}{l}0.199(-1) \\
0.208(-1)\end{array}$ \\
\hline $3 p \rightarrow 6 f$ & $\begin{array}{l}0.717(-3) \\
-\end{array}$ & $\begin{array}{l}0.180(-3) \\
-\end{array}$ & $\begin{array}{l}0.109(-2) \\
-\end{array}$ & $\begin{array}{l}0.199(-2) \\
0.233(-2)\end{array}$ \\
\hline $3 p \rightarrow 7 f$ & $\begin{array}{l}0.121(-3) \\
-\end{array}$ & $\begin{array}{l}0.271(-4) \\
-\end{array}$ & $\begin{array}{l}0.165(-3) \\
-\end{array}$ & $\begin{array}{l}0.313(-3) \\
0.430(-3)\end{array}$ \\
\hline $3 p \rightarrow 8 f$ & $\begin{array}{l}0.245(-4) \\
-\end{array}$ & $\begin{array}{l}0.445(-5) \\
-\end{array}$ & $\begin{array}{l}0.256(-4) \\
-\end{array}$ & $\begin{array}{l}0.545(-4) \\
0.102(-3)\end{array}$ \\
\hline $4 \mathrm{p} \rightarrow 4 \mathrm{f}$ & $\begin{array}{l}0.104(+1) \\
0.105(+1)\end{array}$ & $\begin{array}{l}0.298 \\
0.300\end{array}$ & $\begin{array}{l}0.179(+1) \\
0.180(+1)\end{array}$ & $\begin{array}{l}0.313(+1) \\
0.315(+1)\end{array}$ \\
\hline $4 \mathrm{p} \rightarrow 5 \mathrm{f}$ & $\begin{array}{l}0.141(+1) \\
0.138(+1)\end{array}$ & $\begin{array}{l}0.416 \\
0.394\end{array}$ & $\begin{array}{l}0.250(+1) \\
0.237(+1)\end{array}$ & $\begin{array}{l}0.432(+1) \\
0.414(+1)\end{array}$ \\
\hline $4 \mathrm{p} \rightarrow 6 \mathrm{f}$ & $\begin{array}{l}0.982(-1) \\
0.95(-1)\end{array}$ & $\begin{array}{l}0.277(-1) \\
0.27(-1)\end{array}$ & $\begin{array}{l}0.167 \\
0.163\end{array}$ & $\begin{array}{l}0.293 \\
0.285\end{array}$ \\
\hline $4 p \rightarrow 7 f$ & $\begin{array}{l}0.195(-1) \\
0.19(-1)\end{array}$ & $\begin{array}{l}0.537(-2) \\
-\end{array}$ & $\begin{array}{l}0.323(-1) \\
0.32(-1)\end{array}$ & $\begin{array}{l}0.572(-1) \\
0.564(-1)\end{array}$ \\
\hline $4 p \rightarrow 8 f$ & $\begin{array}{l}0.629(-2) \\
-\end{array}$ & $\begin{array}{l}0.169(-2) \\
-\end{array}$ & $\begin{array}{l}0.101(-1) \\
0.10(-1)\end{array}$ & $\begin{array}{l}0.181(-1) \\
0.182(-1)\end{array}$ \\
\hline
\end{tabular}

The total line strength of the multiplet is equal to the sum of the line strengths of all the multiplet lines

$S\left(\gamma L, \gamma^{\prime} L^{\prime}\right)=\sum S\left(\gamma J, \gamma^{\prime} J^{\prime}\right)$

\section{Results and discussion}

Given the semiempirical character of the RQDO method, quantum defects have to be known. The value of the ionization energy for Ni XVIII was derived by Edlén (1978) from core polarization theory applied to the $n \mathrm{f}$ series. The energy data required as input in our procedure are supplied by the critical compilation by Sugar \& Corliss (1985). For two specific levels, $7 \mathrm{~d}_{3 / 2}$ and $8 \mathrm{f}_{5 / 2}$, there are no energy data available from these authors (Sugar \& Corliss 1985), and they have been taken from Feldman et al. (1971).

In a recent paper, Bhatia \& Drachman (1999) have obtained term energies for high Rydberg states of lithiumlike C IV using a polarization model potential that had Edlén's $(1964,1978)$ as a starting point. However, further corrections of adiabatic and non adiabatic type, intended to account for the energy shift experienced by the outer electron upon interaction with the core, were added. These corrections proved to give a relativistic description of the outer electron's behaviour, and made the model rather more complete than Edlén's (1964, 1978). Nevertheless, for states of high angular momentum $(L>3)$, accurate energies were obtained for C IV with a simplified asymptotic polarizability expansion that included nonadiabatic effects (Bhatia \& Drachman 1999). In the present calculations, the adopted ionization energy value, as reported by Edlén's (1978), although it clearly leaves plenty of room for improvement, is expected to lead to sufficiently correct quantum defects when combined with the reliable energy data compiled by Sugar \& Corliss (1985).

The line and multiplet $S$-values for the electric quadrupole transitions (E2), between doublets of Na-like Ni XVIII, object of the present study, are displayed in Tables 1 to 8 . For each transition for which comparative data were available, two sets of $S$-values are given. One, corresponding to the first entry, obtained with the RQDO formalism. And the other, being the second entry, 
Table 3. continued

\begin{tabular}{|c|c|c|c|c|}
\hline Transition & ${ }^{2} \mathrm{P}_{1 / 2}^{\mathrm{o}}-{ }^{2} \mathrm{~F}_{5 / 2}^{\mathrm{o}}$ & ${ }^{2} \mathrm{P}_{3 / 2}^{\mathrm{o}}-{ }^{2} \mathrm{~F}_{5 / 2}^{\mathrm{o}}$ & ${ }^{2} \mathrm{P}_{3 / 2}-{ }^{2} \mathrm{~F}_{7 / 2}$ & ${ }^{2} \mathrm{P}^{\mathrm{o}}-{ }^{2} \mathrm{~F}^{\mathrm{o}}$ \\
\hline $5 p \rightarrow 5 f$ & $\begin{array}{l}0.100(+2) \\
0.100(+2)\end{array}$ & $\begin{array}{l}0.286(+1) \\
0.287(+1)\end{array}$ & $\begin{array}{l}0.172(+2) \\
0.172(+2)\end{array}$ & $\begin{array}{l}0.301(+2) \\
0.301(+2)\end{array}$ \\
\hline $5 p \rightarrow 6 f$ & $\begin{array}{l}0.602(+1) \\
0.60(+1)\end{array}$ & $\begin{array}{l}0.179(+1) \\
0.170(+1)\end{array}$ & $\begin{array}{l}0.107(+2) \\
0.102(+2)\end{array}$ & $\begin{array}{l}0.185(+2) \\
0.179(+2)\end{array}$ \\
\hline $5 p \rightarrow 7 f$ & $\begin{array}{l}0.509 \\
0.493\end{array}$ & $\begin{array}{l}0.145 \\
0.141\end{array}$ & $\begin{array}{l}0.873 \\
0.85\end{array}$ & $\begin{array}{l}0.153(+1) \\
0.148(+1)\end{array}$ \\
\hline $5 \mathrm{p} \rightarrow 8 \mathrm{f}$ & $\begin{array}{l}0.115 \\
0.110\end{array}$ & $\begin{array}{l}0.322(-1) \\
0.32(-1)\end{array}$ & $\begin{array}{l}0.192 \\
0.189\end{array}$ & $\begin{array}{l}0.339 \\
0.331\end{array}$ \\
\hline $6 \mathrm{p} \rightarrow 6 \mathrm{f}$ & $\begin{array}{l}0.528(+2) \\
0.53(+2)\end{array}$ & $\begin{array}{l}0.151(+2) \\
0.15(+2)\end{array}$ & $\begin{array}{l}0.908(+2) \\
0.91(+2)\end{array}$ & $\begin{array}{l}0.159(+3) \\
0.159(+3)\end{array}$ \\
\hline $6 \mathrm{p} \rightarrow 7 \mathrm{f}$ & $\begin{array}{l}0.198(+2) \\
0.199(+2)\end{array}$ & $\begin{array}{l}0.593(+1) \\
0.57(+1)\end{array}$ & $\begin{array}{l}0.356(+2) \\
0.341(+2)\end{array}$ & $\begin{array}{l}0.613(+2) \\
0.597(+2)\end{array}$ \\
\hline $6 \mathrm{p} \rightarrow 8 \mathrm{f}$ & $\begin{array}{l}0.181(+1) \\
0.176(+1)\end{array}$ & $\begin{array}{l}0.520 \\
0.50\end{array}$ & $\begin{array}{l}0.312(+1) \\
0.301(+1)\end{array}$ & $\begin{array}{l}0.545(+1) \\
0.527(+1)\end{array}$ \\
\hline
\end{tabular}

See footnotes in Table 1.

including results from other sources: The multiplet strengths reported by Tull et al. (1972), and the line strengths from the critical compilation of Fuhr et al. (1988), derived from the former multiplet values (Tull et al. 1972) by using the LS-coupling rules. As already mentioned, the $S$-values from Tull et al. (1972) have been calculated using Hartree-Fock orbital wavefunctions of frozen-core type. No more data of line or multiplet strengths are, to our knowledge, available in the literature.

Results for the $n \mathrm{~s}^{2} \mathrm{~S}-n^{\prime} \mathrm{d}^{2} \mathrm{D}$ transitions with $n=$ 3 and 4 and $n^{\prime}=3-8$ are displayed in Table 1 . We find a fairly good agreement between the RQDO $S$-values and the ones by Tull et al. (1972) for most of the doublet-doublet transitions, the largest discrepancies being of about $10 \%$. The same feature is observed for $n \mathrm{p}^{2} \mathrm{P}^{\mathrm{o}}-n^{\prime} \mathrm{s}^{2} \mathrm{P}^{\mathrm{o}}$ transitions with $n=3-5$ and $n^{\prime}=4-6$ (Table 2), where our data agree satisfactorily with the comparative ones (differing by less than 4\%). An exception is the $3 p-5 p$ transition, but it may be due to a misprint in the article by Tull et al. (1972).

In Table 3 , the $S$-values for the $n \mathrm{p}^{2} \mathrm{P}^{\mathrm{o}}-n \mathrm{f}^{2} \mathrm{~F}^{\mathrm{o}}$ transitions with $n=3-6$ and $n^{\prime}=4-8$ are collected. Again, a general good accord between the set of RQDO $S$-values and those reported by Tull et al. (1972) is found here, with the only exception of a few ones. For the RQDO $3 \mathrm{p}^{2} \mathrm{P}^{\mathrm{o}}-6,7 \mathrm{f}^{2} \mathrm{~F}^{\mathrm{o}}$ multiplet $S$-values, the deviation relative to the comparative line strengths is about $15 \%$ and $27 \%$, respectively. An even larger disagreement is found for the $3 \mathrm{p}^{2} \mathrm{P}^{\mathrm{o}}-8 \mathrm{f}^{2} \mathrm{~F}^{\mathrm{o}}$ multiplet, but this transition appears to be rather weak.

Line strengths for $n \mathrm{~d}^{2} \mathrm{D}-n^{\prime} \mathrm{d}^{2} \mathrm{D}$ transitions are displayed in Table 4. An inspection of this table reveals good similarities in magnitude between our RQDO $S$-values and the comparative ones for all of the transitions, differing by less than $6 \%$.

RQDO results for a few $n \mathrm{~d}^{2} \mathrm{D}-5 \mathrm{~g}{ }^{2} \mathrm{G}$ transitions are included in Table 5. No comparative data have been found for these. However, we expect our values to have the same quality as that for the preceding transitions since no additional complications are present here. In Table 6 , line strengths for $n \mathrm{f}^{2} \mathrm{~F}^{\mathrm{o}}-n^{\prime} \mathrm{p}^{2} \mathrm{P}^{\mathrm{o}}$ transitions are collected, up to the highest ${ }^{2} \mathrm{P}^{\circ}$ level for which energy data was available. The $S$-values collected in Table 7, corresponding to $n \mathrm{f}^{2} \mathrm{~F}^{\mathrm{o}}-n \mathrm{f}^{2} \mathrm{~F}^{\mathrm{o}}$ arrays, show a satisfactory agreement, differing by less than $2 \%$. The RQDO line strengths for a few transitions starting from the $5 \mathrm{~g}^{2} \mathrm{G}_{7 / 2,9 / 2}$ levels are collected in Table 8 , where no comparative data are available.

A general inspection of the tables reveals that our results comply with a feature that is characteristic of the LS coupling scheme: the strongest line within a given LS transition array is the one for which $\Delta J=J-J^{\prime}$ coincides in value with $\Delta L=L^{\prime}-L$, in particular when either $J$ or $J^{\prime}$ is the maximum $J$-value in the array. We take this as a proof of correctness in the RQDO calculations. 
Table 4. Line strengths for the $n \mathrm{~d} \rightarrow n^{\prime} \mathrm{d}$ fine-structure and multiplet transitions

\begin{tabular}{|c|c|c|c|c|c|}
\hline Transition & ${ }^{2} \mathrm{D}_{3 / 2}-{ }^{2} \mathrm{D}_{3 / 2}$ & ${ }^{2} \mathrm{D}_{3 / 2}-{ }^{2} \mathrm{D}_{5 / 2}$ & ${ }^{2} \mathrm{D}_{5 / 2}-{ }^{2} \mathrm{D}_{3 / 2}$ & ${ }^{2} \mathrm{D}_{5 / 2}-{ }^{2} \mathrm{D}_{5 / 2}$ & ${ }^{2} \mathrm{D}-{ }^{2} \mathrm{D}$ \\
\hline $3 \mathrm{~d} \rightarrow 4 \mathrm{~d}$ & $\begin{array}{l}0.382(-1) \\
0.37(-1)\end{array}$ & $\begin{array}{l}0.163(-1) \\
0.16(-1)\end{array}$ & $\begin{array}{l}0.165(-1) \\
0.16(-1)\end{array}$ & $\begin{array}{l}0.658(-1) \\
0.63(-1)\end{array}$ & $\begin{array}{l}0.137 \\
0.131\end{array}$ \\
\hline $3 d \rightarrow 5 d$ & $\begin{array}{l}0.276(-2) \\
-\end{array}$ & $\begin{array}{l}0.118(-2) \\
-\end{array}$ & $\begin{array}{l}0.118(-2) \\
-\end{array}$ & $\begin{array}{l}0.474(-2) \\
-\end{array}$ & $\begin{array}{l}0.987(-2) \\
0.944(-2)\end{array}$ \\
\hline $3 \mathrm{~d} \rightarrow 6 \mathrm{~d}$ & $\begin{array}{l}0.696(-3) \\
-\end{array}$ & $\begin{array}{l}0.299(-3) \\
-\end{array}$ & $\begin{array}{l}0.298(-3) \\
-\end{array}$ & $\begin{array}{l}0.120(-2) \\
-\end{array}$ & $\begin{array}{l}0.249(-2) \\
0.237(-2)\end{array}$ \\
\hline $3 \mathrm{~d} \rightarrow 7 \mathrm{~d}$ & $\begin{array}{l}0.276(-3) \\
-\end{array}$ & $\begin{array}{l}0.121(-3) \\
-\end{array}$ & $\begin{array}{l}0.118(-3) \\
-\end{array}$ & $\begin{array}{l}0.483(-3) \\
-\end{array}$ & $\begin{array}{l}0.997(-3) \\
0.952(-3)\end{array}$ \\
\hline $3 d \rightarrow 8 d$ & $\begin{array}{l}0.143(-3) \\
-\end{array}$ & $\begin{array}{l}0.616(-4) \\
-\end{array}$ & $\begin{array}{l}0.612(-4) \\
-\end{array}$ & $\begin{array}{l}0.246(-3) \\
-\end{array}$ & $\begin{array}{l}0.512(-3) \\
0.485(-3)\end{array}$ \\
\hline $4 d \rightarrow 5 d$ & $\begin{array}{l}0.408 \\
0.406\end{array}$ & $\begin{array}{l}0.174 \\
0.174\end{array}$ & $\begin{array}{l}0.176 \\
0.174\end{array}$ & $\begin{array}{l}0.702 \\
0.70\end{array}$ & $\begin{array}{l}0.146(+1) \\
0.145(+1)\end{array}$ \\
\hline $4 d \rightarrow 6 d$ & $\begin{array}{l}0.285(-1) \\
0.28(-1)\end{array}$ & $\begin{array}{l}0.122(-1) \\
0.12(-1)\end{array}$ & $\begin{array}{l}0.122(-1) \\
0.12(-1)\end{array}$ & $\begin{array}{l}0.489(-1) \\
0.48(-1)\end{array}$ & $\begin{array}{l}0.102 \\
0.996(-1)\end{array}$ \\
\hline $4 \mathrm{~d} \rightarrow 7 \mathrm{~d}$ & $\begin{array}{l}0.684(-2) \\
-\end{array}$ & $\begin{array}{l}0.297(-2) \\
-\end{array}$ & $\begin{array}{l}0.293(-2) \\
-\end{array}$ & $\begin{array}{l}0.119(-1) \\
0.12(-1)\end{array}$ & $\begin{array}{l}0.246(-1) \\
0.240(-1)\end{array}$ \\
\hline $4 d \rightarrow 8 d$ & $\begin{array}{l}0.271(-2) \\
-\end{array}$ & $\begin{array}{l}0.116(-2) \\
-\end{array}$ & $\begin{array}{l}0.116(-2) \\
-\end{array}$ & $\begin{array}{l}0.463(-2) \\
-\end{array}$ & $\begin{array}{l}0.966(-2) \\
0.936(-2)\end{array}$ \\
\hline $5 \mathrm{~d} \rightarrow 6 \mathrm{~d}$ & $\begin{array}{l}0.237(+1) \\
0.237(+1)\end{array}$ & $\begin{array}{l}0.101(+1) \\
0.102(+1)\end{array}$ & $\begin{array}{l}0.102(+1) \\
0.102(+1)\end{array}$ & $\begin{array}{l}0.408(+1) \\
0.406(+1)\end{array}$ & $\begin{array}{l}0.849(+1) \\
0.846(+1)\end{array}$ \\
\hline $5 \mathrm{~d} \rightarrow 7 \mathrm{~d}$ & $\begin{array}{l}0.157 \\
0.155\end{array}$ & $\begin{array}{l}0.672(-1) \\
0.66(-1)\end{array}$ & $\begin{array}{l}0.672(-1) \\
0.66(-1)\end{array}$ & $\begin{array}{l}0.269 \\
0.266\end{array}$ & $\begin{array}{l}0.561 \\
0.554\end{array}$ \\
\hline $5 d \rightarrow 8 d$ & $\begin{array}{l}0.365(-1) \\
0.36(-1)\end{array}$ & $\begin{array}{l}0.157(-1) \\
0.15(-1)\end{array}$ & $\begin{array}{l}0.156(-1) \\
0.15(-1)\end{array}$ & $\begin{array}{l}0.627(-1) \\
0.61(-1)\end{array}$ & $\begin{array}{l}0.131 \\
0.128\end{array}$ \\
\hline $6 \mathrm{~d} \rightarrow 7 \mathrm{~d}$ & $\begin{array}{l}0.101(+2) \\
0.98(+1)\end{array}$ & $\begin{array}{l}0.420(+1) \\
0.421(+1)\end{array}$ & $\begin{array}{l}0.435(+1) \\
0.420(+1)\end{array}$ & $\begin{array}{l}0.169(+2) \\
0.168(+2)\end{array}$ & $\begin{array}{l}0.355(+2) \\
0.351(+2)\end{array}$ \\
\hline $6 \mathrm{~d} \rightarrow 8 \mathrm{~d}$ & $\begin{array}{l}0.619 \\
0.61\end{array}$ & $\begin{array}{l}0.265 \\
0.263\end{array}$ & $\begin{array}{l}0.266 \\
0.263\end{array}$ & $\begin{array}{l}0.106(+1) \\
0.105(+1)\end{array}$ & $\begin{array}{l}0.221(+1) \\
0.219(+1)\end{array}$ \\
\hline $7 \mathrm{~d} \rightarrow 8 \mathrm{~d}$ & $\begin{array}{l}0.318(+2) \\
0.32(+2)\end{array}$ & $\begin{array}{l}0.136(+2) \\
0.14(+2)\end{array}$ & $\begin{array}{l}0.142(+2) \\
0.139(+2)\end{array}$ & $\begin{array}{l}0.563(+2) \\
0.56(+2)\end{array}$ & $\begin{array}{l}0.115(+3) \\
0.116(+3)\end{array}$ \\
\hline
\end{tabular}

See footnotes in Table 1.

A global view of the quality of our results is shown in Fig. 1. We have plotted the deviation of our RQDO data from those reported by Tull et al. (1972). Only the multiplet $S$-values are shown. The graph allows us to see the rather good agreement between the RQDO values and the values reported by Tull et al. (1972). Most of the results show a deviation less than 10 per cent.
In order to apply another test to the quality of our results, we have plotted the RQDO $S$-values, multiplied by $\left(n^{\prime *}\right)^{3}$, against $\left(n^{\prime *}\right)$, the efective quantum number.

It has long been established that for all spectral series of hydrogen or hydrogenlike species, the square of the radial integral, to which the line strength is proportional, diminishes as $n^{\prime-3}$, with $n^{\prime}$ being the principal quantum 
Table 5. Line strengths for the $n \mathrm{~d} \rightarrow 5 \mathrm{~g}$ fine-structure and multiplet transitions

\begin{tabular}{lllll}
\hline Transition & ${ }^{2} \mathrm{D}_{3 / 2}-{ }^{2} \mathrm{G}_{7 / 2}$ & ${ }^{2} \mathrm{D}_{5 / 2}-{ }^{2} \mathrm{G}_{7 / 2}$ & ${ }^{2} \mathrm{D}_{5 / 2}-{ }^{2} \mathrm{G}_{9 / 2}$ & ${ }^{2} \mathrm{D}-{ }^{2} \mathrm{G}$ \\
\hline $3 \mathrm{~d} \rightarrow 5 \mathrm{~g}$ & 0.128 & $0.143(-1)$ & $0.537(+1)$ & $0.552(+1)$ \\
$4 \mathrm{~d} \rightarrow 5 \mathrm{~g}$ & $0.398(+1)$ & 0.444 & $0.167(+3)$ & $0.171(+3)$ \\
$5 \mathrm{~d} \rightarrow 5 \mathrm{~g}$ & $0.766(+1)$ & 0.851 & $0.319(+3)$ & $0.328(+3)$ \\
\hline
\end{tabular}

No comparative data.

Table 6. Line strengths for the $n \mathrm{f} \rightarrow n \mathrm{p}$ fine-structure and multiplet transitions

\begin{tabular}{lllll}
\hline Transition & ${ }^{2} \mathrm{~F}_{5 / 2}^{\mathrm{o}}-{ }^{2} \mathrm{P}_{1 / 2}^{\mathrm{o}}$ & ${ }^{2} \mathrm{~F}_{5 / 2}^{\mathrm{o}}-{ }^{2} \mathrm{P}_{3 / 2}^{\mathrm{o}}$ & ${ }^{2} \mathrm{~F}_{7 / 2}^{\mathrm{o}}-{ }^{2} \mathrm{P}_{3 / 2}^{\mathrm{o}}$ & ${ }^{2} \mathrm{~F}^{\mathrm{o}}-{ }^{2} \mathrm{P}^{\mathrm{o}}$ \\
\hline \multirow{2}{*}{$4 \mathrm{f} \rightarrow 5 \mathrm{p}$} & 0.159 & $0.437(-1)$ & 0.263 & 0.466 \\
& 0.165 & $0.47(-1)$ & 0.282 & 0.494 \\
& & & & \\
$4 \mathrm{f} \rightarrow 6 \mathrm{p}$ & $0.685(-2)$ & $0.194(-2)$ & $0.117(-1)$ & $0.204(-1)$ \\
& - & - & $0.12(-1)$ & $0.218(-1)$ \\
$5 \mathrm{f} \rightarrow 6 \mathrm{p}$ & $0.172(+1)$ & 0.470 & $0.283(+1)$ & $0.502(+1)$ \\
& $0.175(+1)$ & 0.499 & $0.299(+1)$ & $0.524(+1)$ \\
\hline
\end{tabular}

See footnotes in Table 1.

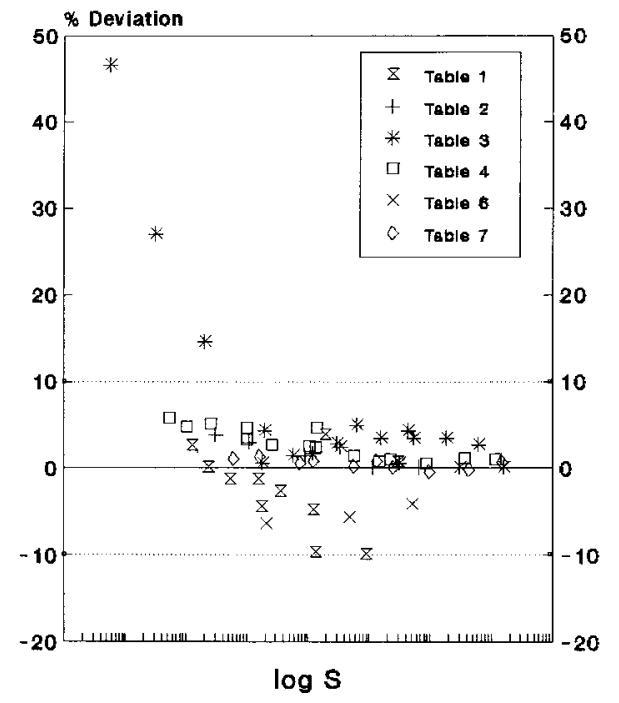

Fig. 1. Relative deviation of the RQDO line strengths for the multiplets

number of the upper state in the transition (Martin \& Wiese 1996 and references therein). If the quantum defects are not small, as in atomic species other than hydrogenlike, $n^{\prime}$ should be replaced by the effective principal quantum number. The variation of the line strength with $n^{\prime *}$ as we advance in an unperturbed spectral series, i.e., for sufficiently high $n^{\prime}$, when the behaviour becomes

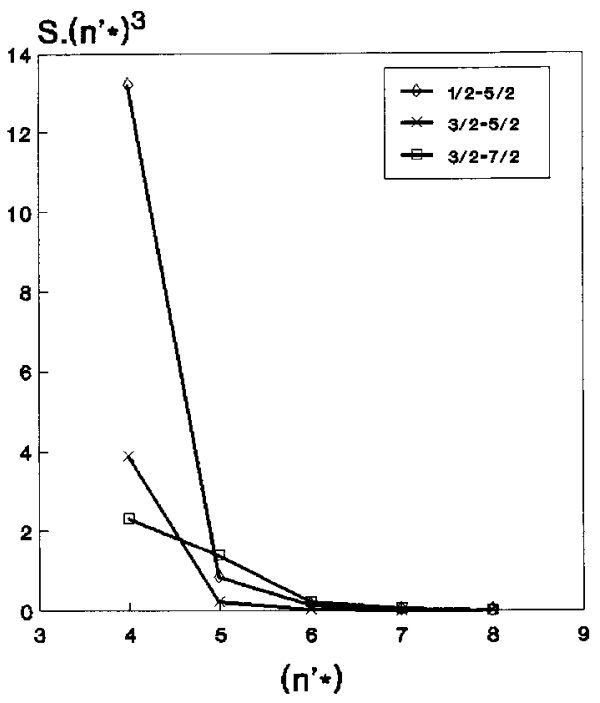

Fig. 2. Regularities in the line strength along the spectral series $3 \mathrm{p}^{2} \mathrm{P}_{1 / 2}-n \mathrm{f}^{2} \mathrm{~F}_{5 / 2}, 3 \mathrm{p}^{2} \mathrm{P}_{3 / 2}-n \mathrm{f}^{2} \mathrm{~F}_{5 / 2}$, and $3 \mathrm{p}^{2} \mathrm{P}_{3 / 2}-n \mathrm{f}^{2} \mathrm{~F}_{7 / 2}$

hydrogenic, satisfies the following expression (Martin \& Wiese 1996):

$S\left(n l j, n^{\prime} l^{\prime} j^{\prime}\right) \propto\left(n^{\prime *}\right)^{-3}$.

In Figs. 2 to 4, the RQDO line strengths multiplied by the third power of the effective quantum number of the final state are plotted against $n^{\prime *}$, for several of the linestructure transitions object of the present work. 
Table 7. Line strengths for the $n \mathrm{f} \rightarrow n^{\prime}$ f fine-structure and multiplet transitions

\begin{tabular}{|c|c|c|c|c|c|}
\hline Transition & ${ }^{2} \mathrm{~F}_{5 / 2}^{\mathrm{o}}-{ }^{2} \mathrm{~F}_{5 / 2}^{\mathrm{o}}$ & ${ }^{2} \mathrm{~F}_{5 / 2}^{\mathrm{O}}-{ }^{2} \mathrm{~F}_{7 / 2}^{\mathrm{O}}$ & ${ }^{2} \mathrm{~F}_{7 / 2}^{\mathrm{O}}-{ }^{2} \mathrm{~F}_{5 / 2}^{\mathrm{o}}$ & ${ }^{2} \mathrm{~F}_{7 / 2}^{\mathrm{o}}-{ }^{2} \mathrm{~F}_{7 / 2}^{\mathrm{o}}$ & ${ }^{2} \mathrm{~F}^{\mathrm{o}}-{ }^{2} \mathrm{~F}^{\mathrm{o}}$ \\
\hline $4 f \rightarrow 5 f$ & $\begin{array}{l}0.482 \\
0.481\end{array}$ & $\begin{array}{l}0.803(-1) \\
0.80(-1)\end{array}$ & $\begin{array}{l}0.806(-1) \\
0.80(-1)\end{array}$ & $\begin{array}{l}0.671 \\
0.67\end{array}$ & $\begin{array}{l}0.132(+1) \\
0.131(+1)\end{array}$ \\
\hline $4 \mathrm{f} \rightarrow 6 \mathrm{f}$ & $\begin{array}{l}0.273(-1) \\
0.27(-1)\end{array}$ & $\begin{array}{l}0.456(-2) \\
-\end{array}$ & $\begin{array}{l}0.455(-2) \\
-\end{array}$ & $\begin{array}{l}0.380(-1) \\
0.38(-1)\end{array}$ & $\begin{array}{l}0.744(-1) \\
0.740(-1)\end{array}$ \\
\hline $4 \mathrm{f} \rightarrow 7 \mathrm{f}$ & $\begin{array}{l}0.595(-2) \\
-\end{array}$ & $\begin{array}{l}0.993(-2) \\
-\end{array}$ & $\begin{array}{l}0.991(-2) \\
-\end{array}$ & $\begin{array}{l}0.827(-2) \\
-\end{array}$ & $\begin{array}{l}0.162(-1) \\
0.160(-1)\end{array}$ \\
\hline $4 \mathrm{f} \rightarrow 8 \mathrm{f}$ & $\begin{array}{l}0.218(-2) \\
-\end{array}$ & $\begin{array}{l}0.362(-3) \\
-\end{array}$ & $\begin{array}{l}0.363(-3) \\
-\end{array}$ & $\begin{array}{l}0.301(-2) \\
-\end{array}$ & $\begin{array}{l}0.591(-2) \\
0.585(-2)\end{array}$ \\
\hline $5 f \rightarrow 6 f$ & $\begin{array}{l}0.351(+1) \\
0.352(+1)\end{array}$ & $\begin{array}{l}0.583 \\
0.59\end{array}$ & $\begin{array}{l}0.586 \\
0.59\end{array}$ & $\begin{array}{l}0.487(+1) \\
0.489(+1)\end{array}$ & $\begin{array}{l}0.954(+1) \\
0.958(+1)\end{array}$ \\
\hline $5 \mathrm{f} \rightarrow 7 \mathrm{f}$ & $\begin{array}{l}0.205 \\
0.205\end{array}$ & $\begin{array}{l}0.342(-1) \\
0.34(-1)\end{array}$ & $\begin{array}{l}0.342(-1) \\
0.34(-1)\end{array}$ & $\begin{array}{l}0.285 \\
0.284\end{array}$ & $\begin{array}{l}0.558 \\
0.557\end{array}$ \\
\hline $5 \mathrm{f} \rightarrow 8 \mathrm{f}$ & $\begin{array}{l}0.444(-1) \\
0.44(-1)\end{array}$ & $\begin{array}{l}0.739(-2) \\
-\end{array}$ & $\begin{array}{l}0.740(-2) \\
-\end{array}$ & $\begin{array}{l}0.615(-1) \\
0.61(-1)\end{array}$ & $\begin{array}{l}0.121 \\
0.120\end{array}$ \\
\hline $6 \mathrm{f} \rightarrow 7 \mathrm{f}$ & $\begin{array}{l}0.157(+2) \\
0.158(+2)\end{array}$ & $\begin{array}{l}0.261(+1) \\
0.263(+1)\end{array}$ & $\begin{array}{l}0.263(+1) \\
0.263(+1)\end{array}$ & $\begin{array}{l}0.218(+2) \\
0.219(+2)\end{array}$ & $\begin{array}{l}0.428(+2) \\
0.429(+2)\end{array}$ \\
\hline $6 \mathrm{f} \rightarrow 8 \mathrm{f}$ & $\begin{array}{l}0.908 \\
0.91\end{array}$ & $\begin{array}{l}0.151 \\
0.151\end{array}$ & $\begin{array}{l}0.152 \\
0.15\end{array}$ & $\begin{array}{l}0.126(+1) \\
0.126(+1)\end{array}$ & $\begin{array}{l}0.247(+1) \\
0.247(+1)\end{array}$ \\
\hline $7 \mathrm{f} \rightarrow 8 \mathrm{f}$ & $\begin{array}{l}0.541(+2) \\
0.54(+2)\end{array}$ & $\begin{array}{l}0.904(+1) \\
0.90(+1)\end{array}$ & $\begin{array}{l}0.903(+1) \\
0.90(+1)\end{array}$ & $\begin{array}{l}0.755(+2) \\
0.75(+2)\end{array}$ & $\begin{array}{l}0.148(+3) \\
0.147(+3)\end{array}$ \\
\hline
\end{tabular}

See footnotes in Table 1.

Table 8. Line strengths for the $5 \mathrm{~g} \rightarrow n$ d fine-structure and multiplet transitions

\begin{tabular}{lllll}
\hline Transition & ${ }^{2} \mathrm{G}_{7 / 2}-{ }^{2} \mathrm{D}_{3 / 2}$ & ${ }^{2} \mathrm{G}_{7 / 2}-{ }^{2} \mathrm{D}_{5 / 2}$ & ${ }^{2} \mathrm{G}_{9 / 2}-{ }^{2} \mathrm{D}_{5 / 2}$ & ${ }^{2} \mathrm{G}-{ }^{2} \mathrm{D}$ \\
\hline $5 \mathrm{~g} \rightarrow 6 \mathrm{~d}$ & 0.414 & $0.457(-1)$ & $0.172(+2)$ & $0.176(+2)$ \\
$5 \mathrm{~g} \rightarrow 7 \mathrm{~d}$ & $0.229(-1)$ & $0.248(-2)$ & 0.934 & 0.959 \\
$5 \mathrm{~g} \rightarrow 8 \mathrm{~d}$ & $0.481(-2)$ & $0.531(-3)$ & 0.200 & 0.205 \\
\hline
\end{tabular}

No comparative data.

It can be observed that the trend followed by our data is such that a constant value is reached as soon as the upper state is suficiently excited to acquire a near-hydrogenic character. This is another proof of the correctness of the RQDO wavefunctions, given that the studied spectral series are free from perturbations by others.

On the basis of the general good agreement between the RQDO and the comparative $S$-values, together with the compliance of the present results with the above mentioned feature of the LS coupling scheme, as well as with the expected systematic trends along different spectral series, we are confident in the potential usefulness of the RQDO procedure for supplying data relative to electric quadrupole transitions, that may be required in astrophysics and fusion plasma research.

\section{Concluding remarks}

The RQDO formalism has been applied to the study of E2 transitions with a recently modified computer code. 


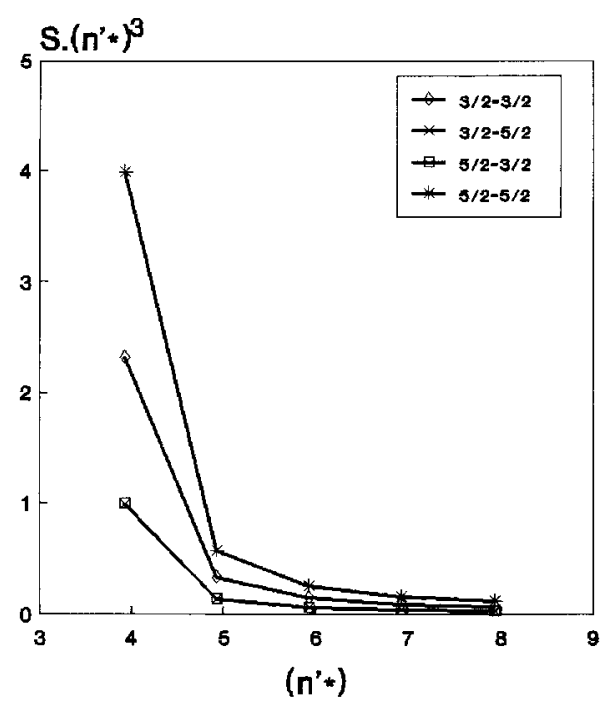

Fig. 3. Regularities in the line strength along the spectral series $3 \mathrm{~d}^{2} \mathrm{D}_{3 / 2}-n \mathrm{~d}^{2} \mathrm{D}_{3 / 2}, 3 \mathrm{~d}^{2} \mathrm{D}_{3 / 2}-n \mathrm{~d}^{2} \mathrm{D}_{5 / 2}, 3 \mathrm{~d}^{2} \mathrm{D}_{5 / 2}-n \mathrm{~d}^{2} \mathrm{D}_{3 / 2}$, and $3 \mathrm{~d}^{2} \mathrm{D}_{5 / 2}-n \mathrm{~d}^{2} \mathrm{D}_{5 / 2}$

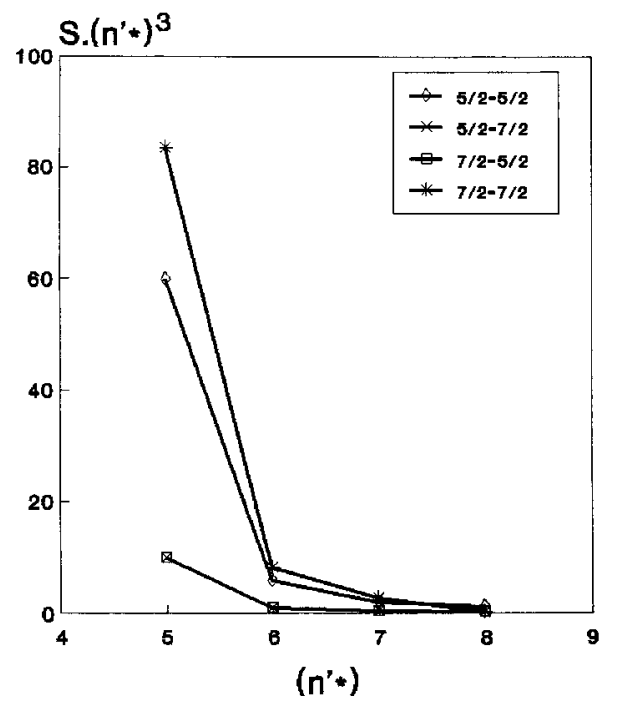

Fig. 4. Regularities in the line strength along the spectral series $4 \mathrm{f}^{2} \mathrm{~F}_{5 / 2}-n \mathrm{f}^{2} \mathrm{~F}_{5 / 2}, 4 \mathrm{f}^{2} \mathrm{~F}_{5 / 2}-n \mathrm{f}^{2} \mathrm{~F}_{7 / 2}, 4 \mathrm{f}^{2} \mathrm{~F}_{7 / 2}-n \mathrm{f}^{2} \mathrm{~F}_{5 / 2}$, and $4 \mathrm{f}^{2} \mathrm{~F}_{7 / 2}-n \mathrm{f}^{2} \mathrm{~F}_{7 / 2}$

The line strengths supplied for several spectral series of Ni XVIII have been analysed. The RQDO procedure has once more proved to be a very useful tool for estimating transition intensities. It is particularly adequate in the cases where mass-production of data is needed, given its cost-efficiency and reasonable accuracy. It offers also the advantage of its analycity and lack of convergence problems from which elaborate ab initio calculations often suffer.

Acknowledgements. This work has been supported by the DGES of the Spanish Ministry of Education within Project No. PB97-0399-C03-01, the J.C.L. within Project No. VA
21/97. DBW thanks Alexander von Humboldt Foundation and the Polish KBN (Project No. 2 PO3B 126 14) for supporting this work.

\section{References}

Baik D.H., Ohr Y.G., Kim K.S., et al., 1991, At. Data Nucl. Data Tables 47, 177

Bhatia A.K., Drachman R.J., 1999, Phys. Rev. A 60, 2848

Biémont E., Dutrieux J.F., Martín I., Quinet P., 1998, J. Phys. B.: At. Mol. Opt. Phys. 31, 3321

Biémont E., Godefroid M., 1978, Phys. Scr. 18, 323

Breton C., DeMichelis C., Finkenthal M., Mattali M., 1979, Euratom Report No. CEA FC 989, Fontenay-aux-Roses

Charro E. López-Ayuso, Martín I., 1999, J. Phys. B.: At. Mol. Opt. Phys. 32, 4555

Charro E., Martín I., 2000a, ApJS 126, 127

Charro E., Martín I., 2000b, ApJS 126, 551

Charro E., Martín I., 1999a, A\&A 343, 634

Charro E., Martín I., 1999b, ApJ 513, 997

Charro E., Martín I., 1998, A\&AS 131, 523

Charro E., Martín I., Lavín C., 1996, J. Quant. Spectrosc. Radiat. Transfer 56, 241

Charro E., Martín I., Lavín C., 1997, A\&AS 124, 397

Charro E., Martín I., Serna M.A., 2000, J. Phys. B 33, 1753

Edlén B., 1964, in Handbuch der Physik. Springer, Berlin, Vol. 27, p. 80

Edlén B., 1978, Phys. Scr. 17, 565

Feldman U., Katz L., Behring W., Cohen L., 1971, J. Opt. Soc. Am. 61, 91

Flower D.R., Nussbaumer H., 1975, A\&A 42, 265

Fuhr J.R., Martin G.A., Wiese W.L., 1988, J. Phys. Chem. Ref. Data 17, Suppl. 4

Godefroid M., Magnusson C.E., Zetterberg P.O., Joelsson I., 1985, Phys. Scr. 32, 125

Janev R.K., 1991, Phys. Scr. 137, 5

Karwowski J., Martín I., 1991, Phys. Rev. A 43, 4832

Keenan F.P., 1992, Newslett. Anal. Astron. Spectra 17, 9

Krueger T.K., Czyzak S.J., 1965, Mem. R. Astron. Soc. 69, 145

Martín I., Karwowski J., 1991, J. Phys. B: At. Mol. Opt. Phys. 24,1538

Martín I., Karwowski J., Diercksen G.H.F., Barrientos C., 1993, A\&AS 100, 595

Martín P., Lavín C., Martín I., 1994, Z. Phys. D: Atoms, Molecules and Clusters 30, 279

Martín I., Simons G., 1975, J. Chem. Phys. 62, 4799

Martín I., Simons G., 1976, Mol. Phys. 32, 1017

Martin W.C., Wiese W.L., 1996, in Drake G.W.F. (ed.), Atomic, Molecular, and Optical Physics Handbook, American Institut of Physics. Woodbury, New York, p. 135

Mohan M., Sharme R., Hibbert A., 1996, Phys. Scr. 54, 352

Nielsen J., 1992, J. Quant. Spectrosc. Radiat. Transfer 47, 171

Sandlin G.D., Bartoe J.D.F., Toursey R., Van Hossier M.E., 1986, A\&AS 61, 601

Simons G., 1974, J. Chem. Phys. 60, 645

Sugar J., Corliss C., 1985, J. Phys. Chem. Ref. Data 14 Suppl. 2, p. 650

Tull C.E., Jackson M., McEachran P., Cohen M., 1972, J. Quant. Spectrosc. Radiat. Transfer 12, 893

Vernazza J.E., Reeves E.M., 1978, ApJS 37, 485

Zhang M.L., Sampson D.H., Clark R.E.H., Mann J.B., 1989, At. Data Nucl. Data Tables 41, 1 